Xue-Mei Yang, Tao Zhu and Long Lin*

\title{
Crystal structure of bis(3-methyl-N-(1-(pyrazin-2- yl)ethylidene)benzohydrazonato- $\left.\mathrm{K}^{3} \mathrm{O}, N, N^{\prime}\right)$ nickel(II), $\mathrm{C}_{28} \mathrm{H}_{26} \mathrm{~N}_{8} \mathrm{O}_{2} \mathrm{Ni}$
}

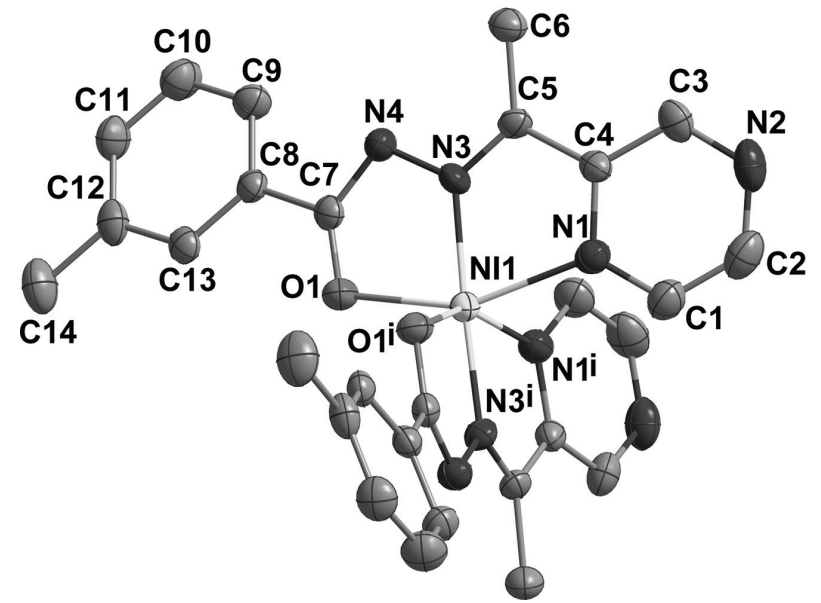

https://doi.org/10.1515/ncrs-2019-0833

Received November 13, 2019; accepted January 13, 2020; available online March 25, 2020

\section{Abstract \\ $\mathrm{C}_{28} \mathrm{H}_{26} \mathrm{~N}_{8} \mathrm{O}_{2} \mathrm{Ni}$, orthorhombic, $A b a 2$ (no. 41), $a=11.813(10) \AA$, $b=21.433(17) \AA, \quad c=10.030(8) \AA, \quad V=2539(4) \AA^{3}, \quad Z=4$, $R_{\mathrm{gt}}(F)=0.0457, w R_{\text {ref }}\left(F^{2}\right)=0.0992, T=296(2) \mathrm{K}$.}

\section{CCDC no.: 1977161}

The molecular structure is shown in the figure (Hydrogen atoms are omitted for clarity). Table 1 contains crystallographic data and Table 2 contains the list of the atoms including atomic coordinates and displacement parameters.

\section{Source of material}

3-Methyl-benzoic acid hydrazide $(0.151 \mathrm{~g}, 1 \mathrm{mmol})$ and 2aceto-pyrazine (0.124 g, $1 \mathrm{mmol})$ were dissolved in methanol

\footnotetext{
*Corresponding author: Long Lin, School of Materials Science and Engineering, Henan Polytechnic University, Jiaozuo 454000, P.R. China, e-mail: linlong@hpu.edu.cn. https://orcid.org/00000003-1645-5600

Xue-Mei Yang: School of Chemical and Environmental Engineering, Jiaozuo University, Jiaozuo 454000, P.R. China

Tao Zhu: Department of Technology, Jiacheng Environmental Protection Engineering Limited Company, Shijiazhuang 050031, P.R. China
}

Table 1: Data collection and handling.

\begin{tabular}{ll}
\hline Crystal: & Black block \\
Size: & $0.17 \times 0.15 \times 0.14 \mathrm{~mm}$ \\
Wavelength: & Mo $K \alpha$ radiation $(0.71073 \AA)$ \\
$\mu:$ & $0.81 \mathrm{~mm}^{-1}$ \\
Diffractometer, scan mode: & Bruker APEX-II, $\varphi$ and $\omega$ \\
$\theta_{\text {max }}$, completeness: & $25.0^{\circ},>99 \%$ \\
$N(h k l)_{\text {measured }}, N(h k l)_{\text {unique }}, R_{\text {int }}:$ & $6034,2012,0.077$ \\
Criterion for $I_{\text {obs }}, N(h k l)_{\text {gt }}:$ & $I_{\text {obs }}>2 \sigma\left(I_{\text {obs }}\right), 1306$ \\
$N(\text { param })_{\text {refined }}:$ & 179 \\
Programs: & Bruker $[1]$, SHELX [2, 3] \\
\hline
\end{tabular}

Table 2: Fractional atomic coordinates and isotropic or equivalent isotropic displacement parameters $\left(\AA^{2}\right)$.

\begin{tabular}{lrrrr}
\hline Atom & $\boldsymbol{x}$ & $\boldsymbol{y}$ & $\boldsymbol{Z}$ & \multicolumn{1}{c}{$\boldsymbol{U}_{\text {iso }}{ }^{*} \boldsymbol{U}_{\text {eq }}$} \\
\hline Ni1 & 0.0000 & 0.5000 & $0.55930(15)$ & $0.0404^{(3)}$ \\
O1 & $0.0102(4)$ & $0.4242(2)$ & $0.4204(5)$ & $0.0507(14)$ \\
N1 & $0.0663(5)$ & $0.5596(3)$ & $0.7183(7)$ & $0.0518(17)$ \\
N2 & $0.1822(8)$ & $0.6144(3)$ & $0.9289(7)$ & $0.072(2)$ \\
N3 & $0.1597(4)$ & $0.4778(2)$ & $0.5641(8)$ & $0.0439(13)$ \\
N4 & $0.1990(5)$ & $0.4298(3)$ & $0.4844(6)$ & $0.0471(15)$ \\
C1 & $0.0130(8)$ & $0.5941(4)$ & $0.8078(9)$ & $0.068(2)$ \\
H1 & -0.0645 & 0.6006 & 0.7994 & $0.081^{*}$ \\
C2 & $0.0698(10)$ & $0.6204(4)$ & $0.9124(10)$ & $0.078(3)$ \\
H2 & 0.0290 & 0.6434 & 0.9747 & $0.094^{*}$ \\
C3 & $0.2374(9)$ & $0.5803(3)$ & $0.8388(8)$ & $0.058(2)$ \\
H3 & 0.3155 & 0.5757 & 0.8460 & $0.069^{*}$ \\
C4 & $0.1796(6)$ & $0.5509(3)$ & $0.7324(7)$ & $0.0432(18)$ \\
C5 & $0.2312(6)$ & $0.5062(3)$ & $0.6400(7)$ & $0.0418(17)$ \\
C6 & $0.3546(6)$ & $0.4930(3)$ & $0.6417(7)$ & $0.056(2)$ \\
H6A & 0.3668 & 0.4498 & 0.6625 & $0.084^{*}$ \\
H6B & 0.3905 & 0.5186 & 0.7079 & $0.084^{*}$ \\
H6C & 0.3862 & 0.5022 & 0.5557 & $0.084^{*}$ \\
C7 & $0.1111(7)$ & $0.4044(4)$ & $0.4200(7)$ & $0.0437(19)$ \\
C8 & $0.1393(6)$ & $0.3458(3)$ & $0.3439(8)$ & $0.0424(17)$ \\
C9 & $0.2404(7)$ & $0.3147(3)$ & $0.3705(8)$ & $0.054(2)$ \\
H9 & 0.2911 & 0.3301 & 0.4333 & $0.065^{*}$ \\
C10 & $0.2637(9)$ & $0.2597(4)$ & $0.3006(14)$ & $0.071(2)$ \\
H10 & 0.3310 & 0.2385 & 0.3168 & $0.085^{*}$ \\
C11 & $0.1895(8)$ & $0.2367(4)$ & $0.2091(9)$ & $0.063(2)$ \\
H11 & 0.2075 & 0.2003 & 0.1632 & $0.075^{*}$ \\
C12 & $0.0875(8)$ & $0.2664(4)$ & $0.1829(7)$ & $0.057(2)$ \\
C13 & $0.0641(6)$ & $0.3216(3)$ & $0.2532(7)$ & $0.047(2)$ \\
H13 & -0.0039 & 0.3423 & 0.2380 & $0.056^{*}$ \\
C14 & $0.0059(8)$ & $0.2374(4)$ & $0.0874(9)$ & $0.084(3)$ \\
H14A & -0.0701 & 0.2441 & 0.1183 & $0.125^{*}$ \\
H14B & 0.0203 & 0.1934 & 0.0815 & $0.125^{*}$ \\
H14C & 0.0149 & 0.2560 & 0.0010 & $0.125^{*}$ \\
\hline & & & &
\end{tabular}


$(20 \mathrm{~mL})$. The reaction mixture was refluxed for $1 \mathrm{~h}$ and cooled to room temperature. Then nickel(II) acetate tetrahydrate ( $0.125 \mathrm{~g}, 0.5 \mathrm{mmol}$ ) was added. After stirring for $1 \mathrm{~h}$, the mixture was filtered and set aside to crystallize for several days, giving black block crystals.

\section{Experimental details}

The structure was solved by direct methods and refined with the SHELX crystallographic software package [3]. The hydrogen atoms were placed at calculated positions and refined as riding atoms with isotropic displacement parameters.

\section{Comment}

As Schiff bases, hydrazones are an important class of ligands with interesting ligation properties due to the presence of several coordination sites, and are widely applied [4]. In particular, pyrazine-contained hydrazone and their metal complexes have been widely investigated mainly due to their excellent biological activities [5-8]. Herein, the title complex is reported, which was characterized by X-ray diffraction in this work.

In the title structure, the asymmetric unit contains a half of the complex with Ni1 atom lying on the two fold rotational axis [symmetry code: (i) $-x,-y+1, z$ ]. The $\mathrm{C}=0$ bond of the hydrazone ligand is enolized, which could be confirmed by the bond length of $\mathrm{C}-\mathrm{O}$ being 1.265(8) $\AA$ [5-7]. All bond distances and angles are in their normal ranges, and can be compared with those in previously reported Co(II) or $\mathrm{Ni}(\mathrm{II})$ complexes with pyrazine hydrazones [6-8] as well as with a corresponding Ni(II) complex [9]. The central Ni(II) ion with a distorted octahedral coordination geometry is surrounded by two anionic ligands with the $\mathrm{ON}_{2}$ donor set for each ligand, which is the most common coordination mode in pyrazine hydrazono complexes [6-8]. As expected, there exist no classical hydrogen bonds in the crystal.

\section{References}

1. Bruker. SMART and SAINT. Bruker AXS Inc., Madison, WI, USA (2007).

2. Sheldrick, G. M.: SHELXT-integrated space-group and crystal-structure determination. Acta Crystallogr. A71 (2015) 3-8.

3. Sheldrick, G. M.: Crystal structure refinement with SHELX. Acta Crystallogr. C71 (2015) 3-8.

4. Dong, W.-K.; Li, X.-L.; Wang, L.; Zhang, Y.; Ding, Y.-J.: A new application of Salamo-type bisoximes: as a relay-sensor for $\mathrm{Zn}^{2+} / \mathrm{Cu}^{2+}$ and its novel complexes for successive sensing of $\mathrm{H}^{+} / \mathrm{OH}^{-}$. Sens. Actuators, B 229 (2016) 370-378.

5. Xu, J.; Zhou, T.; Xu, Z.-Q.; Gu, X.-N.; Wu, W.-N.; Chen, H.; Wang, Y.; Jia, L.; Zhu, T.-F.; Chen, R.-H.: Synthesis, crystal structures and antitumor activities of copper(II) complexes with a 2-acetylpyrazine isonicotinoyl hydrazone ligand. J. Mol. Struct. 1128 (2017) 448-454.

6. Wang, W.-W.; Wang, Y.; Zhang, L.; Song, Y.-F.; Wu, W.-N.; Chen, Z.: Syntheses, crystal structures and DNA-binding properties of $\mathrm{Cu}(\mathrm{II}) / \mathrm{Ni}(\mathrm{II})$ complexes with acylhydrazone ligand bearing pyrazine unit. Chin. J. Inorg. Chem. 35 (2019) 563-568.

7. Hou, X.-F.; Zhao, X.-L.; Zhang, L.; Wu, W.-N.; Wang, Y.: $\mathrm{Co}(\mathrm{II}) / \mathrm{Zn}(\mathrm{II}) / \mathrm{Cu}$ (II) complexes containing hydrazone ligand bearing pyrazine unit: syntheses, crystal structures and fluorescence properties. Chin. J. Inorg. Chem. 34 (2018) 201-205.

8. Huang, W.; Li, Y.; Yong, J.; Liu, Y.; Wu, D.: Hydrazone-based cobalt complexes toward multielectron redox and spin crossover. RSC Adv. 8 (2018) 17159-17167.

9. Wu, H.; Wu, W.-N.: Crystal structure of bis(1-(phenylsulfonyl)-2(1-(pyrazin-2-yl)ethylidene)hydrazin-1-ido- ${ }^{3} N, N^{\prime}, O$ )nickel(II), $\mathrm{C}_{24} \mathrm{H}_{22} \mathrm{~N}_{8} \mathrm{O}_{4} \mathrm{~S}_{2} \mathrm{Ni}$. Z. Kristallogr. NCS 233 (2018) 465-466. 